\title{
A Net-Zero Energy System Solution for Russian Rural Communities
}

\author{
Pio Lombardi ${ }^{1}$, Bartlomiej Arendarski ${ }^{1}$, Konstantin Suslov ${ }^{2}$, Natalia Shamarova ${ }^{2}$, Polina Sokolnikova ${ }^{3}$, Antonio Marco Pantaleo ${ }^{4}$, \\ Przemyslaw Komarnicki ${ }^{5}$
}

${ }^{1}$ Fraunhofer Institute IFF, Sandtorstrasse 22, 39106 Magdeburg, Germany
${ }^{2}$ Irkutsk National Research Technical University, Lermontova str. 83, 664082 Irkutsk, Russia
${ }^{3} 50$ Herzt Transmission Gmbh, Heidestr. 2, 10557 Berlin, Germany
${ }^{4}$ Department of agro-environmental sciences, Piazza Umberto I, 1, 70121 Bari BA, Italy
${ }^{5}$ University of applied science Magdeburg-Stendal, Breitscheidstr. 239114 Magdeburg, Germany

\begin{abstract}
The COP 21 agreement state that the reduction of $\mathrm{CO}_{2}$ emissions will limit the rise of global temperatures and thus the impacts of global warming. Since the energy sector is one of the biggest $\mathrm{CO}_{2}$ emitters, greening it is one of the actions selected to achieve COP 21 targets. Increased generation from renewable sources, however, should entail an increase of flexibility options for integrating renewable energy in the system. The volatility of renewable sources such as wind and sun requires flexible storage units, energy conversion and management techniques as well as active consumer participation to ensure the power system is balanced. In multi-energy systems, the electricity generated by renewables is converted into other energy forms such heat or gas. Rural areas result to be attractive test bench in which multi-energy system could be developed. The objective of this study is to analyze the potential for the development of multi-energy systems in remote Russian communities.
\end{abstract}

\section{Introduction}

The Russian Federation is one of the world's largest emitters of greenhouse gases and producers of fossil fuels. Its energy policy strategies are intended to lower carbon emissions by $25 \%$ to $30 \%$ over 1990 by 2030 . The use of renewables could accelerate achievement of this target. Generation with volatile renewable energy sources (RES) such as wind and solar requires a very flexible system, though. Such flexibility could be established by using energy storage systems 1-2, making consumers more active, and transforming the electric system into microgrids, net-zero energy systems (NZES) and multienergy system (MES) 3-7.

Electricity and heat production alone account for around 25\% of direct global climate change emissions. The transportation and industrial sectors account for another $35 \%$ of global direct emissions. Buildings alone are responsible about $6.4 \%$ of global emissions (see Fig. 1). As referred in 8, these emissions are wholly related to the national contribution based on the development status of a particular country. The higher a country's urbanization rate is, the higher its direct and indirect $\mathrm{CO}_{2}$ emissions are. Appropriate actions must be taken for sustainable development. Improving energy efficiency, increasing the use of renewables, electrifying the transportation and heating sectors can be instrumental in decreasing the carbon footprint.

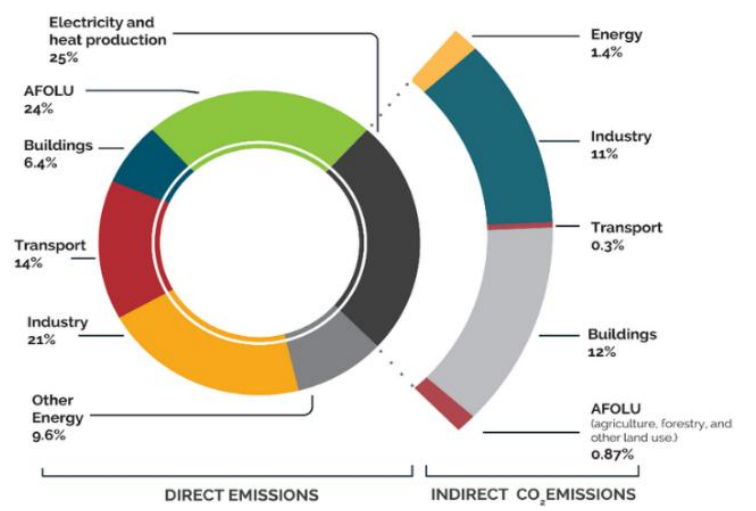

Fig. 1 Direct and indirect $\mathrm{CO}_{2}$ emissions per sector 9

The development of renewable energy systems might be a challenge in the Russian Federation and a solution for greening the Russian energy sector. The Russian Federation has huge capability to exploit its renewable energy resources (see Fig. 2). 


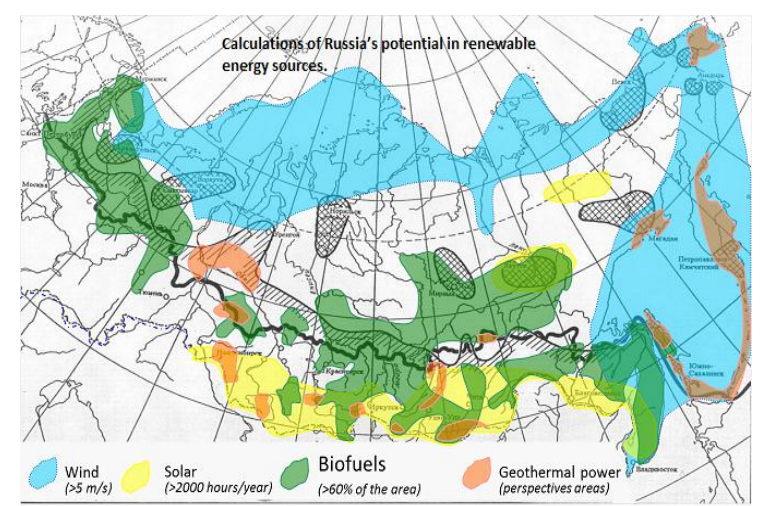

Fig. 2 Potential renewable energy sources in the Russian Federation 10

Power plants based on the photovoltaic technology or on solar thermal collectors could be installed in many areas in the southern part of the Russian Federation and in the Siberian region. Onshore and offshore wind farms could be installed in the northern and eastern coasts. Small or large biomass or biogas power plants could also be used to produce electricity and heat. The potential to exploit (electrical and thermal) energy from biomass is very high (see Table 1). According to 11 , the biomass potential ranges between 1848 and 14084 $\mathrm{PJ} /$ year.

Table 1 Potential biomass feedstock supply in Russia 203011

\begin{tabular}{|l|c|c|}
\hline & $\begin{array}{c}\text { Low } \\
\text { (PT/year) }\end{array}$ & $\begin{array}{c}\text { High } \\
\text { (PT/year) }\end{array}$ \\
\hline Energy crops from non-forest land & - & - \\
\hline Harvest residue & 239 & 493 \\
\hline Agro-processing residue & 218 & 461 \\
\hline $\begin{array}{l}\text { Animal manure and post-consumer } \\
\text { household waste }\end{array}$ & 18 & 498 \\
\hline Energy crops from forest land & 0 & 10386 \\
\hline Timber logging and processing residue & 801 & 1728 \\
\hline $\begin{array}{l}\text { Wood construction, demolition and } \\
\text { furniture waste }\end{array}$ & 572 & 518 \\
\hline Total & 1848 & 14084 \\
\hline
\end{tabular}

\section{Rural Communities in the Russian Federation}

Around 10-15 million people live in rural areas in the Russian Federation. They are mostly located in the north and in the far east of the Russia Federation. Such areas are supplied neither by the electrical grid nor by a natural gas network (see Fig. 3). Over $90 \%$ of the energy consumed in these areas is thermal and less than $10 \%$ is electricity (see Fig. 4). Residents of these areas use diesel generators or biomass boilers to produce electricity and heat. Diesel is generally supplied by train, boat or even helicopter. According to 11, between 900 and 50000 diesel generators are in operation in Russian rural areas. They generate less than $1 \%$ of Russia's total electricity output at a cost that can reach $€ 1 / \mathrm{kWh}$.

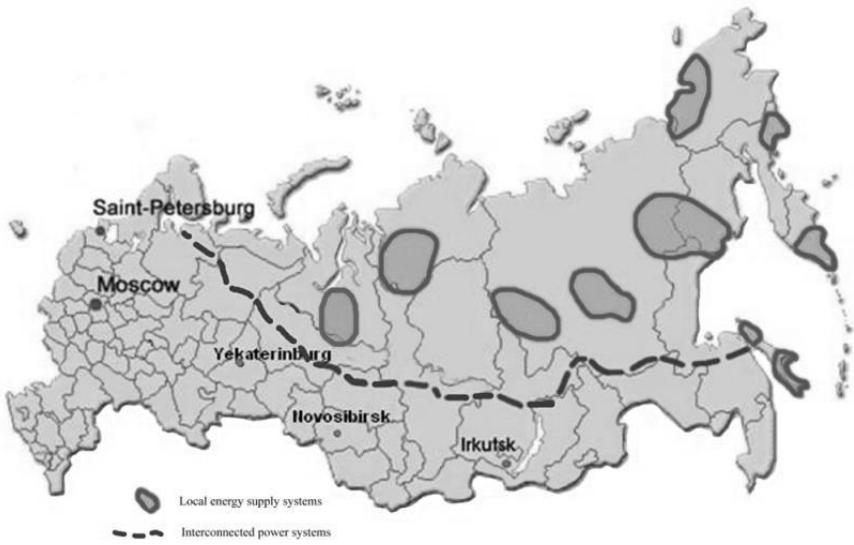

Fig. 3 Remote rural areas in the Russian Federation

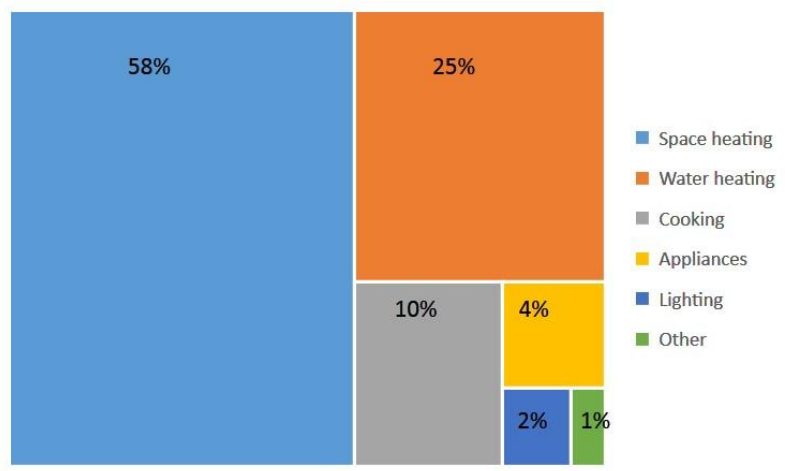

Fig. 4 Energy use in the residential sector (based on 11)

These areas' economies could be vastly improved if the quality of the (electrical and thermal) energy supply was better and the costs were lower than they actually are. Renewable energy sources offer great potential to improve the quality of life in the Russian rural areas. They can help decrease energy generation costs, improve the quality of the energy supply, and create new job opportunities 12 . Since the capital expenditures required to upgrade rural systems from diesel generators to RES generators would be relevant to local investors, it is very important to identify the optimal energy system configuration that maximizes investment economically, socially and technically.

\section{Energy Configuration for Rural Energy Systems}

Renewable generators could become the backbone of rural energy systems. They could supply the energy required by a rural community completely. Doing this, however, requires making the energy system more robust with new flexibility options. Energy storage systems, e.g. batteries or thermal energy storage systems, could help make the system robust enough to integrate volatile RES $100 \%$. Multi-energy systems could conceivably also cover other energy demands such as 
heat, transportation and gas (see Fig. 5). Energy storage systems (electrical and thermal) in MES are key elements for integrating and storing volatile RES for long periods.

Electric vehicles are an attractive solution for distributing energy storage throughout the rural energy system. The electric agricultural machinery such as tractors and vans being marketed by more and more electric vehicle manufacturers could be integrated in the rural electric system perfectly.

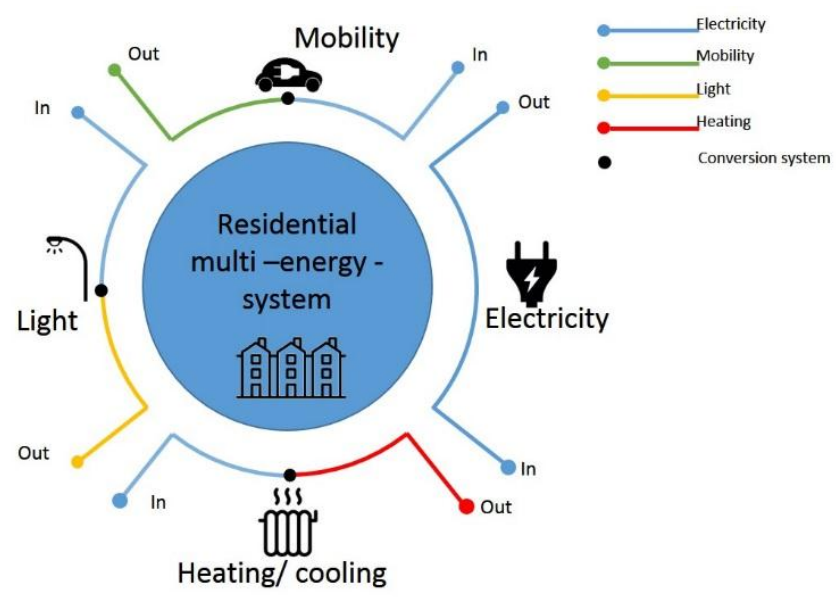

Fig. 5 Residential multi-energy system design

Electric heat pumps and biomass boilers could be selected to produce heat. Electric heat pumps are generally used to convert electricity into low enthalpy heat (up to $55^{\circ} \mathrm{C}$ ). The heat produced can be supplied to the local heat network or stored in thermal energy storage systems (TESS). The heat pumps' energy performance is contingent on the sink side temperature $\left(\mathrm{T}_{\mathrm{H}}\right)$ and the heat source temperature $\left(\mathrm{T}_{\mathrm{L}}\right)$. The coefficient of performance (COP) is normally the main parameter analyzed to evaluate the performances of electric heat pumps (see Eq.(1)). The COP of air/water heat pumps can range between 1.1 and 6.5 (see Table ). Water/water heat pumps do not perform as well as air/water heat pumps but their heat source temperature is more constant over time.

$$
C O P=\frac{E_{\text {heat }}}{E_{\text {electric }}}=\frac{T_{H}}{T_{H}-T_{L}}
$$

Table 2 COP of air/water heat pump

\begin{tabular}{|c|c|c|c|c|c|}
\hline $\begin{array}{c}\text { Heat source } \\
\text { temperature } \\
\text { (K) }\end{array}$ & \multicolumn{5}{|c|}{ Sink side temperature (K) } \\
\hline & 288.15 & 308.15 & 318.15 & 328.15 & 333.15 \\
\hline 253.15 & 3.2 & 1.9 & 1.4 & 1.2 & 1.1 \\
\hline 258.15 & 3.6 & 2.3 & 1.8 & 1.4 & 1.2 \\
\hline 266.15 & 4.0 & 2.9 & 2.5 & 2.1 & 1.9 \\
\hline 275.15 & 4.7 & 3.4 & 2.9 & 2.5 & 2.4 \\
\hline 280.15 & 5.6 & 4.0 & 3.3 & 2.8 & 2.7 \\
\hline 283.15 & 5.5 & 4.1 & 3.5 & 2.9 & 2.7 \\
\hline 288.15 & 6.3 & 4.6 & 3.7 & 3.1 & 2.9 \\
\hline 293.15 & 6.5 & 4.8 & 3.8 & 3.2 & 3.0 \\
\hline
\end{tabular}

Biomass can be burned in boilers or organic Rankine cycle (ORC) plants to increase enthalpy and thus temperature. ORC plans can cogenerate electricity and heat and be connected with solar thermal power plants Ошибка! Источник ссылки не найден.-16. They can also recover waste heat to cogenerate electricity and heat.

\section{Net-Zero Energy System Design}

The net-zero energy system (NZES) design could be a paradigm for upgrading Russian rural energy systems. The idea behind the NZES design is to establish a system supplies every load (electric, heat, transportation, etc.) only by using RES. The time horizon considered is fundamental to the NEZS design. A system could be net-zero for one hour, one week or one year. The longer the time horizon is, the larger the number of flexibility options needed (for energy storage capacity or energy converter capacity) is and, consequently, the higher the capital expenditures needed are.

For rural areas, the methodology applied to design an NZES is generally divided into three phases (see Fig. 6). In the first phase, the system (e.g. buildings, districts, etc.) is analyzed and modeled. In the second phase, the potential to produce renewable energy and the energy loads (electricity, heat, etc.) are estimated. In the third phase, the energy sources and the flexibility options (e.g. energy storage capacity) are modeled over the considered time horizon.

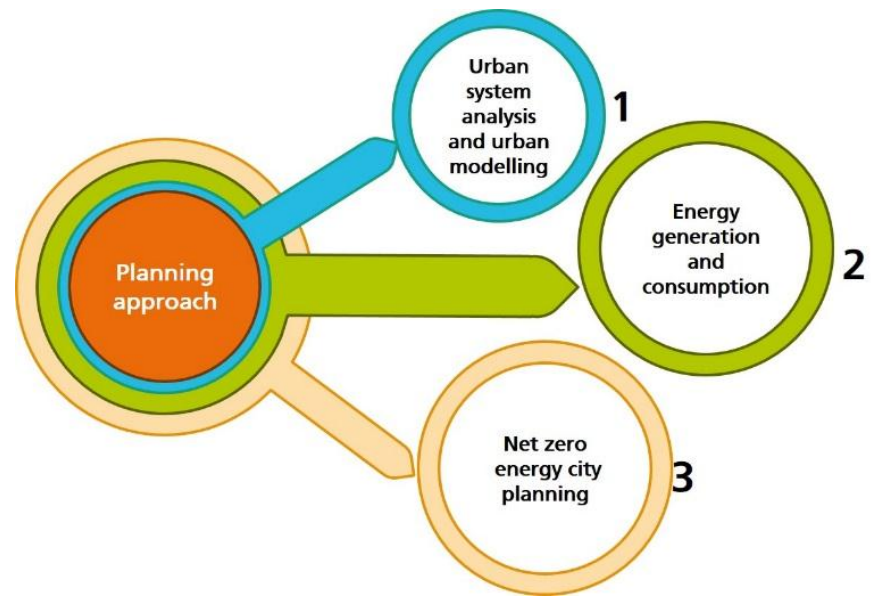

Fig. 6 NZES design methodology

Different modeling and analysis tools were used for phases one and two. Fig. 7 presents an NZES modeled with ESI SimulationX ${ }^{\circledR}$ software. 


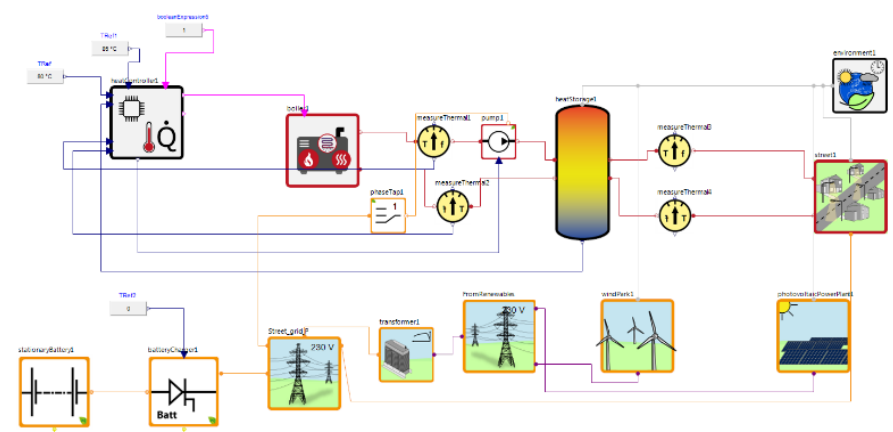

Fig. 7 Screenshot of an NZES modeled with ESI SimulationX ${ }^{\circledR}$ software

Phase three deals with an optimization problem that can be solved by considering only one criteria (generally economic) or various criteria (i.e. economic, technical, social and ecological).Total capital expenditure is usually an economic criterion. Other indicators such as net present value, internal rate of return or cost of generated energy are estimated to assess the cost effectiveness of every single NZES configuration considered. The technical analysis generally entails evaluating the system self-consumption index (SSCI) (see Eq.(2)) and the system self-sufficiency index (SSSI) (see Eq.(3)).

$$
\begin{aligned}
& S S C I=\frac{\int_{t=t_{1}}^{t_{2}} \min \left\{\operatorname{Load}(t), R E S_{\text {gen }}(t)\right\} d t}{\int_{t=t_{1}}^{t_{2}} R E S_{\text {gen }}(t) d t} \\
& S S S I=\frac{\int_{t=t_{1}}^{t_{2}} \min \left\{\operatorname{Load}(t), R E S_{\text {gen }}(t)\right\} d t}{\int_{t=t_{1}}^{t_{2}} \operatorname{Load}(t) d t}
\end{aligned}
$$

A variety of indicators can be factored into the social analysis. New job opportunities created by investment and visual or acoustic impacts of new infrastructures on a system are usually analyzed indicators. Virtual reality and 3D tools can be used to facilitate communication of a new infrastructure's visual impact on an existing system to local communities (see Fig. 8)

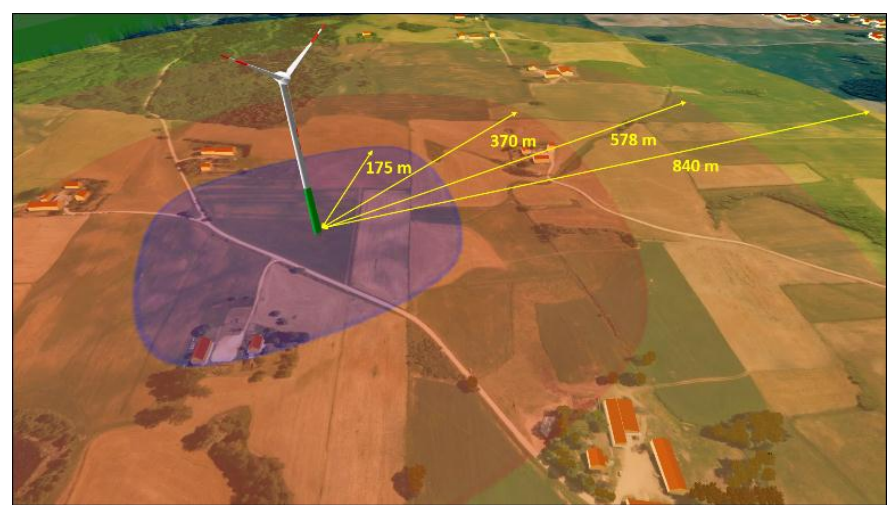

Fig. 8 Visual impact of a wind park represented by a virtual reality tool
Emissions and reductions are analyzable ecological criteria. $\mathrm{CO}_{2}, \mathrm{CO}_{2}$ equivalents or particulate matter are usually evaluated. Though these indicators, the quality of the air in which the new generators will be installed can be performed.

\section{Conclusion}

Over 10 million Russians live in remote communities that are not supplied by the main electrical grid. Electricity in these areas is largely produced by diesel generators with fuel transported in by train, boat or helicopter. Consequently, the costs of producing electricity are very high. Russia is very rich in natural energy resources. Biomass, sun and wind resources could be exploited to supply energy for electricity, heat and transportation. Multi-energy systems could be designed to modernize existing infrastructures. Electrification of the entire energy system could help increase the penetration of power generated by RES. MES offer sufficient flexibility to implement net-zero energy systems. Designing generators and flexibility options for net-zero energy would improve the quality and certainty of supply. It is essential to consider technical, economic and social factors when designing an NZES. The latter factor should be considered carefully since it can expedite or hinder the implementation of an NZES project.

\section{Acknowledgments}

The authors gratefully acknowledge funding for this research from the ERA-Net Smart Grids Plus initiative, with support from the EU's H2020.

\section{References}

1. P. Komarnicki, P. Lombardi and Z. Styczynski, "Electric Energy Storage Systems: Flexibility Options for Smart Grid", Springer, (2017).

2. N. Hatziargyriou, W. Yadusky, J. Taylor, B. Bak-Jensen, M. Barlow, G. Joos, A. Rotheram, C. Schwaegerl, P. Lombardi, S. Venkataraman, F. Cazzato, Z. Lu, P. Papadopoulos, S. Skarvelis-Kazakos, L. Cocchi, D. Stamatiadis, J. Yoshinaga, M. Negnevitsky, I. Inkwan Hong, J. Radhakrishna Pillai, V. Kleftakis, A. Baitch, "The impact of battery energy storage systems on distribution networks", CIGRE-International Council on Large Energy Systems, (2018)

3. P. Lombardi, P. Sokolnikova, B. Arendarski, R. Franke, A. Hoepfner, P. Komarnicki, "Multi-criteria planning tool for a net zero energy village", $18^{\text {th }}$ IEEE EEEIC Conference, Palermo, (2018)

4. P. Mancarella, "MES (multi-energy systems): An overview of concepts and evaluation models". Energy, 65, 1-17, (2014).

5. N. Good, E. A. A, Cesena, L. Zhang, P. Mancarella, "Techno-economic and business cases assessment of low carbo and technologies in distributed multi-energy systems", Applied energy, 167, 158-172

6. C. Marnay, S. Chatzivasileiadis, C. Abbey, R. Iravani, G. Joos, P. Lombardi, P. Mancarella, J. von Appen, 
"Microgrid evolution roadmap", 2015 International Symposium on Smart Electric Distribution Systems and Technologies (EDST), (2015)

7. P. Lombardi, Z. Styczynski, T. Sokolnikova, K. Suslov, "Use of energy storage in Isolated Micro Grids", Power Systems Computation Conference (PSCC),( 2014)

8. J. Poppim, J. Bahru, "Urban-Rural Inequalities in Carbon Emissions", Cambridge/Rio, (2017).

9. J. Blocher, "Water always Flows Downhill: A Case for Participatory Forest Management (PFM) and Decentralization of Forest Governance in REDD+ Implementation", Climate and Environmental Challenges, (2016).

10. Green Capacity. available on www.greencapacity.ru

11. International Renewable Energy Agency (IRENA), "REMP 2030 Renewable Energy Prospects from The Russian Federation", (2017)

12. P. Lombardi, T. Sokolnikova, K. Susolov, N. Voropai, Z.A. Styczynski, "Isolated Power System in Russia. A chance for renewable energies?", Renewable Energy, volume 90, pages 532-541, (2016)
13. Pantaleo, A. M., Camporeale, S. M., Miliozzi, A., Russo, V., Shah, N., \& Markides, C. N. (2017). Novel hybrid CSP-biomass CHP for flexible generation: Thermoeconomic analysis and profitability assessment. Applied Energy, http://doi.org/10.1016/j.apenergy.2017.05.019

204.

14. M. Liu, K. H van Dam, A. M. Pantaleo, M. Guo, "Optimisation of Integrated Bioenergy and Concentrated Solar Power Supply Chains in South Africa", Computer Aided Chemical Enginering, Volume 43, pages 1463 1468

15. A.M. Pantaleo, S. Giarola, A. Bauen, N. Shah, "Integration of biomass into urban energy systems for heat and power. Part I: An MILP based spatial optimization methodology“, Energy Conversion and Management, Volume 83, pages 347-361, (2014)

16. A.M. Pantaleo, S. Giarola, A. Bauen, N. Shah, "Integration of biomass into urban energy systems for heat and power. Part II: Sensitivity assessment of main techno-economic factors", Energy Conversion and Management, Volume 83, pages 347-361, (2014). 